and insist upon, higher standards. The planter of the future must be taught to think and to understand his economic and biological universe. This is realised at the West Indian Agricultural College, but are we going to live up to it? Will such an outlook receive the support of tropical public opinion on which we are so largely dependent for funds? Is it, for the present, to be expected? It is therefore important that the matter should be appreciated by scientific opinion in this country to which scientific workers in the Crown Colonies look very largely for encouragement and protection.

Reference to research has been purposely avoided in the above observations for the sake of simplicity. But research, the mother of scientific education, has also its disabilities in the tropics. Up till quite recently, the demand, the popular demand, has been for " trouble-curing" rather than research. The present danger, however, is that research work may be interfered with through depriving investigators of their time in order that they may give instruction.

West Indian Agricultural College, W. R. DUNLOP. I4 Trinity Square, E.C.3.

Gravitation and Light-Pressure in Nebulæ.

IN NATURE of June 16 there is a most interesting letter by Dr. Jeans on my suggestion that spiral nebulæ may consist of dust repelled from the stars by light-pressure. My original note must, I fear, have been somewhat misleading to have called forth the particular criticism which Dr. Jeans's letter contains. As was, I think, brought out in the discussion at the Royal Astronomical Society, it was never my intention to suggest that the dust clouds are so thick that there is any appreciable shielding; indeed it is perfectly obvious, as Dr. Jeans points out, that the whole theory would break down unless the particles are assumed to be so far apart that they can be treated individually.

The misunderstanding is due to a somewhat ambiguous sentence at the end of the paper, which I admit is capable of giving quite a wrong impression. I had anticipated that my suggestion would be criticised unless I presented some explanation of the so-called "novæ" in spirals. The suggestion put forward was that they were similar to terrestrial meteoritic showers. In order to show that this was not impossible I put in some very rough quantities, and endeavoured to show that they would not lead to absurd results for the characteristics of the nebula. The density found, based, it may be remarked, upon the time in which the meteoritic stones are supposed to evaporate, leads to a mass over the depth of one light-year of O.I grams per square centimetre. I agree, of course, that this cannot be supported by radiation pressure; indeed a remark by me to the same effect may be found in the Observatory some years ago. It would have been better had I said that this result was some $10^{3}$ times too high in view of the obvious transparency of parts of the spirals. The great uncertainty of the quantities used, however, emboldened me to say this was of the right order of magnitude; compared with the results derived from other hypotheses to account for the " novæ," which led to results $10^{6}$ times greater, this was perhaps excusable.

Dr. Jeans's criticism, to which $\mathrm{I}$ admit my somewhat optimistic sentence laid me open, applies, therefore, to that part of my paper from which this unduly large mass was derived; i.e. the hypotheses introduced to account for the " novæe." It is possible that the quantities which I used might be altered plausibly to give a more acceptable value. It is perhaps even more likely that a more satisfactory hypothesis may be evolved to account for the phenomenon. But the main outlines of my suggestion do not seem to be controverted.

Clarendon Laboratory, Oxford F. A. LINDEMANN. June I6.

The Heape and Grylls Rapid Ginema.

OWING to arrangements deemed necessary at the Soirée of the Royal Society on June 20 , I was unfortunately deprived of the opportunity I had hoped there to gain, of making a personal explanation which is important to me and which I beg to be allowed to make in NATURE.

The conception of devising a camera wherewith photographs could be taken at the rate of 5000 a sec. occurred to me in consequence of some chance remarks made to me by an official of one of the great armament-producing companies in this country. The lion's share of credit for the successful completion of the design of the camera, however, is due to my friend Mr. Horace B. Grylls, who became partner with me in this adventure in I9I 4; while both of us are indebted to my friend Prof. Boys, who, as all who know him will readily believe, gave us with both hands all the help and advice he had to give.

The interest which has lately been aroused by the exhibition of some of the films I took while the machine was still in Messrs. Thos. Cooke and Sons' workshop in York-experimental films and far from perfect, I regret to say-calls for some such statement as I now, with great satisfaction, make here.

Manor Lodge, Tunbridge Wells, WALter Heape. June $2 \mathrm{I}$.

\section{Adsorption and Hamoglobin.}

Sir William Bayliss has pointed out, in Nature for May I9, p. 666, that he is unable to find any account of experiments on the dissociation curve of hæmoglobin at gas pressures considerably greater than that at which the hæmoglobin is presumed to be saturated. He seems to imply that there is no proof that hamoglobin cannot take up more gas than is required by the theory that a chemical compound is formed, in which one molecule of $\mathrm{O}_{2}$ or $\mathrm{CO}$ corresponds to one atom of iron.

The point is important, not only as evidence on the relative merits of the chemical and adsorption theories, but also because experimental methods of determining the oxygen dissociation curve depend on the assumption that hæmoglobin becomes completely saturated, in contact with air, at the ordinary temperature of the laboratory.

I have tried to test this question by shaking equal samples of the same blood (partly reduced) in the Barcroft differential apparatus, (I) with the bottle filled with air in the ordinary way, and (2) with the bottle filled with a mixture of air and $\mathrm{CO}$, containing rather more than half an atmosphere of $\mathrm{CO}$.

It is known that hæmoglobin takes up $\mathrm{CO}$ more than 200 times as readily as oxygen, so the effective gas pressures in the two cases were in the ratio of at least $500: x$. If the hæmoglobin takes up gas by adsorption, one would expect to find appreciably more $\mathrm{CO}$ taken up than oxygen. As a matter of fact, a little more $\mathrm{CO}$ was taken up, but only that quantity which is accounted for by the difference of solubility of $\mathrm{CO}$ and air in the liquids present (blood and dilute sodium carbonate solution).

There was no evidence that the hæmoglobin itself No. 2800 , VOL. I I I ] 